Published in final edited form as:

Nat Med. 2014 August ; 20(8): 904-910. doi:10.1038/nm.3583.

\title{
Asfotase-a improves bone growth, mineralization and strength in mouse models of neurofibromatosis type-1
}

\author{
Jean de la Croix Ndong ${ }^{1,2}$, Alexander James Makowski ${ }^{1,3,4,12}$, Sasidhar Uppuganti ${ }^{1,4}$, \\ Guillaume Vignaux $^{1,2}$, Koichiro Ono ${ }^{1,2,5}$, Daniel S. Perrien ${ }^{1,4,6,12}$, Simon Joubert ${ }^{7}$, Serena \\ R. Baglio ${ }^{8}$, Donatella Granchi ${ }^{8}$, David A. Stevenson ${ }^{9}$, Jonathan J. Rios ${ }^{10,11}$, Jeffry S. \\ Nyman $^{1,3,4,12}$, Florent Elefteriou $1,2,13,14$ \\ ${ }^{1}$ Vanderbilt Center for Bone Biology, Vanderbilt University Medical Center, Nashville, TN 37232 , \\ USA
}

${ }^{2}$ Department of Medicine, Vanderbilt University Medical Center, Nashville, TN 37232, USA

${ }^{3}$ Department of Biomedical Engineering, Vanderbilt University, Nashville, TN 37232, USA

${ }^{4}$ Department of Orthopaedic Surgery \& Rehabilitation, Vanderbilt University Medical Center, Nashville, TN 37232, USA

${ }^{5}$ Nihon Koukan Hospital, Department of Orthopaedic, Spinal Surgery Section-Kawasaki, Kanagawa, Japan

${ }^{6}$ Vanderbilt University Institute of Imaging Sciences, Vanderbilt University Medical Center, Nashville, TN 37232, USA

${ }^{7}$ Alexion Montreal Corp., 2901 Rachel east, suite 23, Montreal, Quebec, H1W4A4, Canada

${ }^{8}$ Laboratory for Orthopedic Pathophysiology and Regenerative Medicine, Istituto Ortopedico Rizzoli, via di Barbiano 1/10, Bologna, Italy

${ }^{9}$ Department of Pediatrics, Division of Medical Genetics, University of Utah, Salt Lake City, UT, USA

${ }^{10}$ Sarah M. and Charles E. Seay Center for Musculoskeletal Research, Texas Scottish Rite Hospital for Children, 2222 Welborn Street, Dallas, Texas 75219, USA

${ }^{11}$ Department of Pediatrics, Eugene McDermott Center for Human Growth \& Development, Department of Orthopaedic Surgery, UT Southwestern Medical Center, Dallas, TX 75390, USA

${ }^{12}$ Department of Veterans Affairs, Tennessee Valley Healthcare System, Nashville, TN, USA

${ }^{13}$ Department of Pharmacology, Vanderbilt University Medical Center, Nashville, TN 37232, USA

Users may view, print, copy, and download text and data-mine the content in such documents, for the purposes of academic research, subject always to the full Conditions of use:http://www.nature.com/authors/editorial_policies/license.html\#terms

Corresponding author: Florent Elefteriou, PhD, Vanderbilt University Medical Center, 2215 Garland Avenue, Light Hall, Room 1255D, Nashville, TN37232-0575, USA, Fax: 615-343-2611, Phone: 615-322-7975, florent.elefteriou@ vanderbilt.edu.

Author contributions statement F.E. and J.C.N. designed the study; J.C.N., A.J.M, S.U., G.V., K.O., J.J.R., D.A.S., S.R.B., D.G., J.S.N. performed experiments; D.S. collected and analyzed data; S.J. provided reagents; F.E. and J.C.D. wrote the manuscript.

D.S. has received honoraria from Alexion for consultation on hypophosphatasia.

The content is solely the responsibility of the authors and does not necessarily represent the official views of the National Institutes of Health or Government. 
${ }^{14}$ Department of Cancer Biology, Vanderbilt University Medical Center, Nashville, TN 37232, USA

\section{Abstract}

Mineralization of the skeleton depends on the balance between levels of pyrophosphate (PPi), an inhibitor of hydroxyapatite formation, and phosphate generated from PPi breakdown by alkaline phosphatase (ALP). We report here that ablation of $N f 1$, encoding the RAS/GTPase-activating protein neurofibromin, in bone-forming cells leads to supraphysiologic PPi accumulation, caused by a chronic ERK-dependent increase in genes promoting PPi synthesis and extracellular transport, namely Enpp1 and Ank. It also prevents BMP2-induced osteoprogenitor differentiation and, consequently, expression of ALP and PPi breakdown, further contributing to PPi accumulation. The short stature, impaired bone mineralization and strength in mice lacking $N f 1$ in osteochondroprogenitors or osteoblasts could be corrected by enzyme therapy aimed at reducing PPi concentration. These results establish neurofibromin as an essential regulator of bone mineralization, suggest that altered PPi homeostasis contributes to the skeletal dysplasiae associated with neurofibromatosis type-1 (NF1), and that some of the NF1 skeletal conditions might be preventable pharmacologically.

\section{Keywords}

bone mineralization; neurofibromin; Neurofibromatosis type I; osteoblast; mesenchymal stem cell; pyrophosphate; Ank; Enpp1/PC1

\section{INTRODUCTION}

Mutations in the $N F 1$ gene cause neurofibromatosis type I (NF1), a genetic disorder with an incidence of $1 / 3500$ worldwide. This condition is characterized by malignant and nonmalignant pathologies, including skeletal manifestations ${ }^{1-6}$. Dystrophic scoliosis, tibia bowing, bone fragility, fracture and pseudarthrosis (non-union following fracture) are skeletal conditions associated with high morbidity in this population ${ }^{7-10}$. Despite recent progress in our understanding of the role of $N F 1$ in skeletal tissues, it is still unclear why and how these bone pathologies arise, raising uncertainty regarding optimal treatment ${ }^{2,3}$.

While NF1 individuals are typically born with heterozygous mutations in NF1, loss of heterozygosity has been detected in pseudarthrosis biopsies ${ }^{11}$, suggesting that local somatic NF1 loss of function contributes to NF1 skeletal dysplasia. This point is further supported by the relative commonality of defects observed between NF1 pseudarthrosis biopsies and the skeleton of NF1 loss-of-function conditional mouse models, which tend to recapitulate, in their entire skeleton, the genetic and cellular consequences of local $N F 1$ loss of function occurring in human NF1 pseudarthroses. Nf1 inactivation in osteochondroprogenitors, in $N f 1^{\mathrm{f} / \mathrm{f}}$; PrX 1 -cre or $\mathrm{Nf} 1^{\mathrm{f} / \mathrm{f}} ;$ Col2a1-cre mice (called herein Prx-Nf1 KO or Col2-Nf1 KO mice, respectively) indeed led to reduced stature, low bone mass, tibia bowing, diaphyseal ectopic blood vessel formation and hypomineralization associated with weakened bone mechanical properties, and indicated that neurofibromin is required for normal osteoblast differentiation and for the control of Rankl expression and osteoclastogenesis ${ }^{12-17}$. The coexistence of $N f 1$-deficient osteoblasts in a $N f 1$ heterozygote bone microenvironment was also shown to 
cause bone loss and delayed bone healing in $N f 1^{\mathrm{f} / \mathrm{f}} ;$ Collal-cre mice $($ Coll-Nf1 KO) via activation of TGF $\beta$ signaling ${ }^{18,19}$. Importantly, each of these NF1 models, as well as bone biopsies from individuals with NF1 pseudarthrosis ${ }^{20}$, are characterized by excessive unmineralized bone matrix (osteoid), despite normal serum phosphate and calcium concentration.

Bone matrix mineralization is a tightly regulated process and requires collagen, calcium and phosphate to form hydroxyapatite, as well as tissue-nonspecific alkaline phosphatase (ALP) activity to hydrolyze pyrophosphate ( $\mathrm{PPi}$, a potent inhibitor of mineralization) and generate inorganic phosphate ${ }^{21}$. Extracellular concentrations of PPi are determined by (1) its degradation via ALP, (2) synthesis catalyzed by the nucleoside triphosphate pyrophosphohydrolase PC-1/ENPP1 (called ENPP1 herein), and (3) its transport into the extracellular milieu through the PPi channel $\mathrm{ANK}^{22}$. Mineralization is also controlled by Phospho1, a phosphatase that provides intracellular inorganic phosphate to generate $\mathrm{PPi}^{23}$, and by glycoproteins such as osteopontin, which inhibits crystal nucleation on collagen fibers in mineralizing vesicles ${ }^{24,25}$. Multiple growth factors such as TGF $\beta$, activin A, BMP2, IGF1, FGF2 and FGF23 are involved in bone and/or cartilage mineralization ${ }^{26-34}$. A common signaling pathway engaged by these factors is the RAS/ERK pathway, which is constitutively activated in cells lacking neurofibromin, the RAS-GTPase Activating Protein (GAP) encoded by $\mathrm{NF}^{35}$. We thus hypothesized that neurofibromin, via its inhibitory action on RAS/ERK signaling in bone-forming cells, could be an important regulator of bone matrix mineralization.

\section{RESULTS}

\section{Uncontrolled PPi production in Nf1-deficient bone cells}

To address if and how $N f 1$ regulates bone mineralization, we first asked whether $N f 1$ ablation in bone marrow stromal cells (BMSCs) affects extracellular PPi concentrations. BMSCs from Col2- $N f 1 \mathrm{KO}$ mice, lacking $N f 1$ in osteochondroprogenitor cells, were characterized by a $60-70 \%$ lower $N f 1$ expression compared to WT mice (Fig. 1a), consistent with the heterogeneous nature of these cultures ${ }^{36}$. This lower $N f 1$ expression level was accompanied by a significant $70 \%$ higher extracellular PPI concentration in the conditioned medium (CM) of undifferentiated BMSC cultures compared to WT controls (Fig. 1b). Addition of a recombinant form of ALP (sALP-FcD10, $0.5 \mu \mathrm{g} . \mathrm{ml}^{-1}$, see below) to induce PPi hydrolysis significantly reduced the amount of PPi detected in both genotypes, confirming the validity of the PPi measurements.

High extracellular PPi concentration can be generated by increased production of PPi by the ectonucleophosphatase ENPP1 and by increased cellular export through the transporter ANK. The expression of both Ank and Enpp1 mRNA (Fig. 1c, left and middle panels) and protein levels (Supplementary Fig. 1a) were higher in Nf1-deficient BMSCs compared to WT BMSCs. Osteopontin (Opn) expression was also higher in Nf1-deficient BMSCs (Fig. 1c, right panel), consistent with the reported stimulatory effect of PPi on $O p n$ expression ${ }^{25}$. We obtained similar results when comparing $N f f^{\text {flox/flox }}$ BMSCs cultures infected with a Cre-expressing adenovirus ( $N f 1$-deficient cells) to control cultures infected by a GFPexpressing adenovirus (Supplementary Fig. 1b), confirming that the changes in gene 
expression measured in BMSCs from Col2-Nf1 KO mice were not caused by a reduced number of osteoprogenitors initially platted. Ank, Enpp1 and Opn expression was also significantly higher in long bones, calvariae and epiphyses (cartilage) from 3 week-old Col2$N f 1 K O$ versus WT mice (Fig. 1d), whereas Runx 2 and Alpl expression was lower (Supplementary Fig. 1c). Lastly, MEK inhibition (U0126, $1 \mu \mathrm{M}, 24 \mathrm{~h}$ ) blunted the increase in Ank, Enppl and Opn expression observed in Nf1-deficient BMSCs (Fig. 1c and Supplementary Fig. 1b).

In an effort to assess whether these molecular findings were conserved from mice to humans, we obtained RNA from human bone adherent stromal cells prepared from 6 control and 9 NF1 tibial pseudarthrosis biopsies, and measured ENPP1 and $A N K$ transcript levels by qPCR. Consistent with the mouse data, ENPP1 expression was significantly higher in cultured cells from NF1 pseudarthrosis tissues (Fig. 1e), despite the small number of available samples and the cell heterogeneity of these cultures. $A N K$ expression, however, was variable between samples and not significantly different between cultures from normal and NF1 pseudarthrosis biopsies (Fig. 1f).

Mice lacking $N f 1$ in mature osteoblasts (Col1-Nf1 KO) have a uniform distribution of nonmineralized matrix throughout trabecular bone compartments ${ }^{18}$, whereas mice lacking $N f 1$ in osteochondroprogenitors and chondrocytes are characterized by an osteoid preferentially distributed in the primary spongiosa, where osteoblasts and chondrocytes mineralize their matrix (Fig. 2a). Based on these observations and because neurofibromin is expressed in hypertrophic chondrocytes ${ }^{37,38}$, we hypothesized that this RAS-GAP could also contribute to cartilage mineralization, which is a process important for bone growth and ossification during development and bone healing in adults. In support of this hypothesis, Col2-Nf1 KO chondrocyte high-density micromass cultures generated a typical Alcian blue-positive matrix but did not show signs of mineralization, in contrast to WT chondrocyte cultures (Fig. 2b). In addition, Ank, Enppl and Opn expression was significantly higher in $\mathrm{Nfl}$ deficient micromass chondrocyte cultures versus WT cultures (Fig. 2c), in agreement with the data obtained from cartilaginous epiphyses, which contain a high proportion of chondrocytes (Fig. 1d). Accordingly, extracellular PPi concentration (Fig. 2d) and Enpp1 enzymatic activity (Fig. 2e) were significantly higher, whereas ALP activity was lower (Fig. 2f) in Nf1-deficient versus WT chondrocytes.

\section{Lack of Nf1 in BMSCs impairs BMP2 osteogenic action}

BMSCs isolated from Col2-Nf1 KO mice displayed, compared to BMSCs isolated from WT mice, a significantly lower differentiation potential, as measured by lower CFU-Ob colony number, TNSAP activity (Fig. 3a) and lower expression of osteoblast differentiation markers including Runx2, $A l p l$ and $O c n$ (Fig. 3b). Similar results were obtained using $N f f^{\text {flox/flox }}$ BMSCs infected with a cre-adenovirus (Supplementary Figs. 1d and e). In contrast to what was observed in the case of Ank and Enpp1 expression, however, MEK inhibition by U0126 $(1 \mu \mathrm{M})$, Tremetinib or PD198306 (0.1 $\mu \mathrm{M}$ and $200 \mathrm{nM}$, respectively, data not shown) for 24 h did not correct the expression level of Runx2 or Alpl in Nf1-deficient BMSCs (Figs. 3c), indicating that the expression of these two genes is not directly controlled by neurofibromin. 
Extracellular PPi concentration, as well as Ank, Enpp1 and Opn expression, remained above or equal to WT controls throughout the differentiation period (Fig. 3d and e).

Bone morphogenic proteins (BMPs) are known for their ability to promote osteoprogenitor differentiation ${ }^{39}$ but had limited effect on the differentiation of $\mathrm{Nf1+/}$ osteoprogenitors and on bone union in $N f 1+/-$ mice $^{40,41}$. Recombinant hBMP2 $\left(100 \mathrm{ng}^{-\mathrm{ml}^{-1}}\right)$ was unable to stimulate ALP activity, nor the formation of CFU-Ob in BMSC cultures from Col2-Nf1 KO mice, although it did, as expected, promote CFU-Ob formation and ALP activity in WT BMSC cultures, following 2 weeks of treatment (Fig. 4a). Smad1/5/8 phosphorylation in response to BMP2 treatment (100 ng.ml ${ }^{-1}, 1$ h) was not affected by $N f 1$ deficiency (Fig. 4b), indicating that the lack of stimulatory effect of BMP2 on Nf1-deficient BMSC differentiation is not caused by repression of BMP2 receptor expression, or by the production of factor(s) inhibiting canonical signaling. Treatment with rhBMP2 for 2 weeks also failed to increase the expression of Alpl, Runx2, and Colla1 in BMSC cultures from Col2-Nf1 KO mice (Fig. 4c). However, it significantly increased the expression of Ank and Enpp1 (but not $O p n$ ) (Fig. 4d) and PPi extracellular concentration (Fig. 4e) in both WT and Nf1-deficient BMSCs. CFU-Ob formation, ALP activity (Figs. 4f and g) and the expression of Alpl and Collal (Supplementary Figs. 2a and b) in Nf1-deficient BMSC cultures were higher following a 2 week-long combined treatment with the MEK inhibitor U0126 (1 $\mu \mathrm{M})$ and BMP2 (100 ng.ml $\left.{ }^{-1}\right)$, but not with either of these treatments alone. This combination treatment also partially reduced the increased Ank, Enpp1 and PPi extracellular concentration detected in vehicle-treated Nf1-deficient BMSC cultures, possibly due to the antagonistic effect of these two drugs on Ank and Enpp1 expression (Supplementary Figs 2c and d).

\section{sALP-FcD10 improves bone growth and BMD in Col2-Nf1 KO mice}

If excessive extracellular PPi levels cause the mineralization deficit observed in Col2-Nf1 $K O$ mice, then reducing PPi concentration should have beneficial effects on matrix mineralization. This is experimentally possible by inhibiting PPi generation or increasing its catabolism. The latter approach was chosen because PPi is a substrate for ALP and a recombinant form of human ALP (sALP-FcD10 or Asfotase- $a$ ) is clinically available to treat $A L P L$-deficient subjects with hypophosphatasia ${ }^{42,43}$. We thus treated WT and Nf1deficient BMSCs with vehicle or SALP-FcD10 $\left(0.5 \mathrm{mg} \cdot \mathrm{ml}^{-1}\right)$ in osteogenic condition for 14 days and assessed matrix mineralization. As predicted, sALP-FcD10 increased matrix mineralization in both genotypes, although the relative increase was more pronounced in cultures from Col2-Nf1 KO versus WT mice (Fig. 5a), and despite the persistent differentiation deficit of $N f 1$-deficient BMSCs in the presence of SALP-FcD10 (Supplementary Fig. 3a). This treatment reduced Opn expression in Nf1-deficient BMSCs (Supplementary Fig. 3a), in agreement with the known stimulatory effect of PPi on $O p n$ expression $^{25}$.

Based on these encouraging results, we treated Col2-Nf1 KO newborn mice daily by subcutaneous injections of sALP-FcD10 (8.2 mg/kg/day) for 18 days ${ }^{44,45}$. Col2-Nf1 KO mice exhibit short stature, low bone mass, mineralization, cortical thickness and mineral density (BMD), and high cortical porosity ${ }^{37}$. Following this short treatment (dictated by the 
relatively high lethality of these mice at weaning), a significant $73 \%$ increase in the size of mutant mice (Fig. 5b) and a clear increase in vertebral and tibial BMD were observed on radiographs (Fig. 5c and d). sALP-FcD10 significantly increased mid-diaphyseal cortical bone thickness, as measured by $3 \mathrm{D}$-microcomputed tomography $(\mu \mathrm{CT})$ (Fig. 5e), partially rescued the formation of secondary ossification centers, expanded tibia metaphyseal envelopes and increased the amount of calcified matrix in the growth plate hypertrophic zone of Col2-Nf1 KO mice (hBV/TV, Fig. 5f). Despite the seemingly pronounced effects of sALP-FcD10 observed by radiography and $\mu \mathrm{CT}$, tibia cortical tissue mineral density and mineral-to-collagen ratio (Supplementary Fig. 3b and c) were not increased following treatment.

\section{sALP-FcD10 increases bone mineralization in Osx-Nf1 KO mice}

Because Col2-Nf1 KO mice manifest severe developmental phenotypes that limit their survival, and thus the duration of treatments, we generated mice in which $N f 1$ can be ablated postnatally in osteoprogenitors, using the inducible Tet-off-based $O s X$-cre transgenic mice ${ }^{46}$ crossed to $N f f^{f / f}$ mice ${ }^{47}$. This new mouse model makes it possible to dissect the mechanisms by which postnatal $N f 1$ ablation impairs bone homeostasis, without complications arising from developmental phenotypes. $O s x-N f 1_{O s X} f / f$ mice had a size undistinguishable from WT littermates upon doxycycline administration (i.e. cre-recombinase repression) from conception to day 14 (Fig. 6a) and had normal phosphate, calcium and 25OH vitamin D serum concentrations (Supplementary Table 1). OsX-cre-mediated $N f 1$ ablation in osteoprogenitors at post-natal day 14 following doxycycline withdrawal, as seen in Col2Nf1 KO mice, caused hyperosteoidosis (Fig. 6b), low bone mass (Fig. 6c), higher femoral diaphyseal cortical porosity (Fig. 6d), lower cortical thickness, mid-shaft moment of inertia and cortical TMD (Fig. 6e-g). Cortical mineral-to-collagen ratio measured by Raman spectroscopy (Fig. 6h) was also lower in $O s X-N f 1 \mathrm{KO}$ mice, and femurs from OsX-Nf1 KO mice were mechanically weaker than those from WT controls, as measured by a 3-point bending tests (Supplementary Table 2).

To assess the effect of sALP-FcD10 on the skeleton of this mouse model, we administered sALP-FcD10 daily from 2 weeks of age (at the time of $N f 1$ ablation) and for 6 weeks. sALP-FcD10 significantly increased trabecular BV/TV and moment of inertia, assessed by $\mu \mathrm{CT}$ (Fig. 6c and f), as well as femoral stiffness, modulus and peak force, measured by $3-$ point-bending (Supplementary Table 2), and led to a non-significant trend for higher cortical femoral thickness (Fig. 6e). sALP-FcD10 improved bone mineralization in OsX-Nf1 $\mathrm{KO}$ mice, as measured by a drastic $73 \%$ reduction in osteoid volume per bone volume, a $65 \%$ reduction in osteoid surface per bone surface, a 53\% decrease in osteoid thickness (Fig. 6b) and a $20 \%$ increase in mineral-to-collagen ratio (Fig. 6h).

\section{Discussion}

We show here that the RAS-GAP activity of neurofibromin in the bone mesenchymal lineage restrains the expression of Enppl and Ank, two main genes controlling PPi homeostasis, and that increasing pyrophosphate catabolism through enzyme therapy significantly improves bone mineralization and bone mechanical properties in mouse models 
of NF1 skeletal dysplasia. These results, along with suggestive evidence of conservation of function between mice and humans, support the causal role of increased PPi levels in the etiology of NF1 hyperosteoidosis, and position neurofibromin as a critical and obligatory regulator of cartilage and bone mineralization. They also provide pre-clinical evidence that some of the most clinically challenging NF1-related skeletal maladies may be amenable to prevention.

Hyperactive TGF $\beta$ signaling was proposed to cause bone loss and to delay bone healing in mice deficient for $N f 1$ in mature osteoblasts and heterozygote for $\mathrm{NfI}^{+/-}$globally ${ }^{19}$. TGF $\beta$ is also known to stimulate ERK activity, Ank and Enpp1 expression and to increase PPi concentration in WT chondrocytes ${ }^{48,49}$. Therefore, $N F 1$-deficient BMSCs may contribute cell-autonomously and/or in a hyperactive TGF $\beta$ paracrine fashion to the extraphysiological skeletal accumulation of PPi and to the impaired osteoblast differentiation and matrix mineralization observed in the setting of NF1. The beneficial effect of sALP-FcD10 on bone growth, mineralization and strength observed in this study suggests that PPi accumulation and abnormal mineralization are important components of NF1 bone dysplasia. However, further studies will be necessary to determine the evolution and contribution of all the cellular defects typical of $N f 1$-deficient bone cells on bone mass and strength over extended periods of treatment with $\mathrm{SALP}-\mathrm{FcD} 10$, as this drug does not correct the differentiation phenotype of Nf1-deficient osteoblasts. Although TGF $\beta$ blockade might theoretically serve as a target to promote bone union in individuals with NF1 pseudarthrosis, the cancer-prone status of this pediatric population and the known tumor suppressor activity of TGF $\beta$ signaling limit this therapeutic approach ${ }^{50}$. Our results, on the other hand, suggest that stimulation of pyrophosphate catabolism through enzyme therapy could be applied on a more chronic basis prior to fracture to strengthen the NF1 dysplastic bones and prevent their mechanical failure.

The mineralization deficit of $N f 1$-deficient BMSCs could be detected in immature BMSCs, prior to their differentiation into osteoblasts. Therefore, this phenotype cannot be attributed to the reduced differentiation potential of Nf1-deficient BMSCs, although the latter certainly contributes to the low bone mass phenotype observed in the two NF1 mouse models used in this study. It is also worth noting that BMP2 treatment, without the need of ERK blockade, stimulated the expression of Ank and Enpp1, as well as extracellular PPi concentration, in $N f 1$-deficient BMSCs, as shown previously in WT cells ${ }^{28}$. This observation could explain why rhBMP2 alone did not improve bone healing in NF1 mouse models ${ }^{40,41}$ and bone union in individuals with NF1 pseudarthrosis ${ }^{51-53}$.

Our results indicate that $N f 1$-deficient BMSCs are not responsive to BMP2 with regard to their differentiation potential and suggest that this defect may in part underlie their inability to differentiate. In addition, the response of $N f 1$-deficient BMSCs to BMP2 with regard to Ank and Enpp1 expression suggests that neurofibromin is not the sole negative regulator of the RAS/ERK signaling pathway upstream of these two genes. These results also indicate that the stimulatory effect of BMP2 on osteoprogenitor differentiation requires controlled ERK signaling by neurofibromin. 
It is unknown to what extent poor matrix mineralization contributes to the low BMD, tibia bowing, poor mechanical properties and possibly pseudarthrosis observed in children with NF1. Although local PPi concentration could not be quantified, the observed increase in the expression of ENPP1 measured in BMSCs extracted from NF1 pseudarthrosis biopsies, as well as the presence of thick osteoid seams on histological sections ${ }^{20}$, supports conservation of function between mice and humans.

Pseudarthrosis and possibly dystrophic scoliosis can currently be treated only by invasive, and often repetitive, surgical orthopedic interventions ${ }^{2,3}$. Most approaches to date are corrective in nature, and only bracing techniques are available to reduce the incidence and severity of these complications. Of major interest is the possibility that SALP-FcD10, if applied preventatively, might improve mineralization, growth, architecture and mechanical properties of dysplastic bones affected by NF1 and, thus, limit their likelihood of deformation and fracture. This latter point is particularly important, as the current standard for treatment is limited to avoidance of prophylactic surgery and early long-term bracing to prevent fracture until skeletal maturity is reached. It is worth emphasizing that sALP-FcD10 is bone-targeted and already successfully utilized in the clinic to treat children with hypophosphatasia ${ }^{42}$. Therefore, its potential use in the context of NF1 skeletal dysplasia could be accelerated compared to other drugs.

\section{Methods}

\section{Animals and drugs}

All procedures were approved by the Vanderbilt University Medical Center Institutional Animal Care and Use Committee (IACUC). WT and Col2-Nf1 KO mice were generated by crossing $\mathrm{Nf} f^{\text {flox/flox }}$ mice and $\mathrm{Nf} \mathrm{f}^{\text {flox/++}} ;$ a l(II) collagen-Cre breeders ${ }^{54,55}$. Nf $f^{\text {flox/flox }}$ mice and $N f f^{\text {flox/flox }}$ mice; a 1(II) collagen-Cre mice were used as WT and cKO, respectively. OsX-Nf1 KO mice were generated by breeding doxycycline-fed $O s X$-cre; $N f f^{\text {flox/flox }}$ mice with $N f f^{\text {flox/flox }}$ breeders ${ }^{47}$. All mice were on a C57BL/6 background. sALP-FcD10 (Asfotase Alfa, Alexion Pharmaceuticals) was described previously ${ }^{56}$. Briefly, mineraltargeting recombinant tissue nonspecific alkaline phosphatase (ALP, sALP-FcD10) was produced in CHO cells by modifying the coding sequence of human ALPL. The GPI anchor sequence of the hydrophobic C-terminal domain of human ALPL was removed to generate a soluble, secreted enzyme (sALP). Then the human $A L P L$ ectodomain sequence was extended with the coding sequence encoding the $\mathrm{Fc}$ region of human $\operatorname{IgG} 1(\mathrm{Fc})$. Finally the $\mathrm{C}$-terminus of the $\mathrm{Fc}$ region was extended with ten aspartic acid residues (D10). The dose of $8.2 \mathrm{mg} . \mathrm{kg}^{-1}$ per day was selected because it was previously shown to be efficacious in shortterm (16 days) efficacy study in $A k p 2-/-$ mice $^{56}$. The specific activity of the lot used in the present study was 878 Units.mg $^{-1}$. sALP-FcD10 was administered subcutaneously for the periods of time indicated in the text.

\section{Human subjects}

The study was approved by the Institutional Review Board of the University of Texas Southwestern Medical Center, the Rizzoli Orthopaedic Institute (Bologna, Italy) and Vanderbilt University. Bone tissues were obtained from 9 patients with NF1 and tibial 
pseudarthrosis (aged between 7 months and 18 years) and 6 controls from children without NF1 who underwent surgery for congenital dysplasia of the hip without any other coexisting pathology $(n=3)^{57}$ or scoliosis $(n=3)$ (aged between 3.3 and 17 years). Diagnosis of pseudarthrosis was based on radiographic and clinical findings. Diagnosis of NF1 was performed according to the criteria presented at the National Institute of Health Consensus Development Conference on Neurofibromatosis [http://consensus.nih.gov/ 1987/1987Neurofibramatosis064html.htm].

\section{Cell culture}

Mouse BMSCs were extracted from long bones by spinning down diaphyses at $1500 \mathrm{rpm}$ for $3 \mathrm{~min}$. Cells were then counted, plated at a density of $10^{6}$ cells $/$ well ( $12 \mathrm{w}$ plates) or $2 \times 10^{6}$ cells/well (6 well plates), and grown for 7 days in aMEM supplemented with 10\% FBS, 100 I.U./ml penicillin, $100 \mu \mathrm{g} / \mathrm{ml}$ streptomycin (Cellgro, Manassas, VA, USA). At day 7, differentiation and mineralization was induced by the addition of $50 \mu \mathrm{g} / \mathrm{ml}$ ascorbic acid and $10 \mathrm{mM} \beta$-glycerophosphate, and the media was refreshed every $2-3$ days. BMSCs differentiation and mineralization were assessed by ALP activity and Alizarin red S staining, respectively, using standard protocols.

Primary chondrocytes were extracted from 4-day-old pup rib bones. The cartilaginous part of the rib was dissected and soft tissues removed, then digested by collagenase D $(3 \mathrm{mg} / \mathrm{ml}$, Roche, USA) and $0.25 \%$ trypsin/ethylenediaminetetraacetic acid (EDTA) (Gibco, USA) in DMEM for $3 \mathrm{~h}$. At confluence, $5 \times 10 \mu \mathrm{l}$ drops of concentrated cells $\left(2 \times 10^{7}\right.$ cells $\left./ \mathrm{ml}\right)$ were plated in 6-wells. After 2 hours of incubation, $2 \mathrm{ml}$ of complete cell culture medium was delicately added. Cells were differentiated in DMEM supplemented with 10\% FBS, 100 IU.ml ${ }^{-1}$ penicillin, $100 \mu \mathrm{g} \cdot \mathrm{ml}^{-1}$ streptomycin, $50 \mu \mathrm{g} \cdot \mathrm{ml}^{-1}$ of ascorbic acid and $10 \mathrm{mM} \beta$ glycerophosphate.

Human cells extracted from bone marrow ${ }^{57}$ or bone tissue were maintained in alpha MEM supplemented with $10 \% \mathrm{FBS}, 100 \mathrm{U} \cdot \mathrm{ml}^{-1}$ penicillin, $0.1 \mathrm{mg} \cdot \mathrm{ml}^{-1}$ streptomycin at $37{ }^{\circ} \mathrm{C}$ in a $5 \% \mathrm{CO}$-humidified atmosphere. Cells from bone tissues were digested overnight with collagenase before platting. After 4 days, non-adherent cells were removed and adherent bone cells were grown until confluence or passaged before RNA extraction.

\section{Adenovirus Infection of BMSCs}

BMSCs were isolated from $N f f^{\text {flox/flox }}$ mice and seeded at a density of $10^{6}$ cells/well in $12 \mathrm{w}$ plates. At 40\% confluence, cells were incubated in complete culture medium (a-MEM, 10\% FBS and $100 \mathrm{IU} \cdot \mathrm{ml}^{-1}$ penicillin) containing either Ad5-CMV-GFP or Ad5-CMV-cre (Vector development lab, Baylor College of Medicine) at $2.5 \times 10^{9}$ PFUs. After 2 days of incubation, the medium was refreshed with complete culture medium. $N f 1$ recombination efficiency was determined according to Wang et $a \beta^{7}$.

\section{Serum vitamin D, calcium and phosphate assays}

Blood samples were collected from WT and Osx-Nf1 KO mice at sacrifice. Vitamin D, phosphate and calcium concentration in mouse serum was determined using a $25 \mathrm{OH}$ Vitamin-D ELISA Assay kit (Eagle Biosciences, cat\# VID31-K01), a Phosphate Assay kit 
(BioVision, cat \# k410-500) and a Calcium Assay kit (BioVision, cat\# k380-250), respectively, according to the manufacturer's instructions.

\section{PPi and PC-1 assays}

PPi release in cell-conditioned media (ePPi) was measured radiometrically using differential adsorption on activated charcoal of Uridine-diphospho-D-glucose $\left[6-{ }^{3} \mathrm{H}\right](\mathrm{Cat}$ \#NET1163250UC, Perkin Elmer) as previously described ${ }^{49,58,59}$. Forty microliters of conditioned medium (or blank control) and $120 \mu \mathrm{l}$ of assay solution ( $57 \mathrm{nM}$ of Tris acetate, pH7.6; 5.2 mM MgAc; 18.6 $\mu \mathrm{M}$ Glucose 1,6-diphosphate (G1,6DP); $9 \mu \mathrm{M}$ Uridinediphosphoglucose (UDPG); $4 \mu \mathrm{M} \beta$-Nicotinamide adenine dinucleotide (NAD+); $0.136 \mathrm{U}$. Uridine-diphosphoglucose pyrophosphorylase (UDPGPP); 0.5 U. phosphoglucomutase; 0.5 U. Glucose-6-phosphate dehydrogenase (G6PD); $0.02 \mu \mathrm{Ci}{ }^{3} \mathrm{H}-\mathrm{UDPG}$ ) were incubated at $37^{\circ} \mathrm{C}$ for $1 \mathrm{~h}$, then adsorbed on $200 \mu \mathrm{l}$ of charcoal for 10 minutes on ice. After centrifugation at $14,000 \mathrm{rpm}$ for 10 minutes, $100 \mu \mathrm{l}$ of the supernatant was transferred into a vial containing $5 \mathrm{ml}$ of Bio-safe II for radioactivity count. PPi levels were normalized by protein concentration in cell lysates in each well. Measurements were performed in triplicate and similar results were obtained from at least 3 independent experiments.

ENPP1 activity was determined using $1.5 \mathrm{mM}$ of the synthetic chromogenic substrate thymidine $5^{\prime}$-monophosphate p-nitrophenyl ester in reaction buffer $(100 \mathrm{mM}$ Tris/ $\mathrm{HCl}, \mathrm{pH}$ $8.0,130 \mathrm{mM} \mathrm{NaCl}$, and $15 \mathrm{mM} \mathrm{MgCl}_{2}$ ) incubated at $37^{\circ} \mathrm{C}$ for $30 \mathrm{~min}$. The reaction was terminated by the addition of $50 \mu \mathrm{l} 4 \mathrm{~N} \mathrm{NaOH}$. Product formation was monitored by measurement of absorbance at $405 \mathrm{~nm}$. ENPP1 activity in each well was normalized by cell number. Measurements were performed in triplicate and from at least 3 independent experiments.

\section{RT-qPCR and genomic PCR}

Total RNA was extracted using TRIzol (Invitrogen, Grand Island, NY, USA) and cDNAs were synthesized from $1 \mu \mathrm{g}$ of RNA following DNase I treatment using the high-capacity cDNA reverse-transcription kit (Applied Biosystems, USA). Quantitative PCR (qPCR) was performed by using TaqMan or SYBR green gene expression assays. The probe and primer sets for mouse Runx2(Mm00501578_m1); Alpl(Mm00475834_m1); Ank (Mm00445047_m1); Enpp1 (Mm00501097_m1); Opn (Mm00436767_m1), Igf1 (Mm01228180_m1), human ANKH(Hs00219798_m1) and human ENPP1 (Hs01054040_m1) and the normalizers Hprt (Mm00446968_m1); human GAPDH (Hs99999905_m1) were obtained from Applied Biosystems (Foster City, CA, USA). The SYBR green primers were: $O p n$ (forward; CTCCTTGCGCCACAGAATG, reverse; TGGGCAACAGGGATGACA), $N f 1$ (forward; GTATTGAATTGAAGCACCTTTGTTTGG, reverse; CTGCCCAAGGCTCCCCCAG); Ocn (forward; ACCCTGGCTGCGCTCTGTCTCT, reverse; GATGCGTTTGTAGGCGGTCTTCA) and Collal (forward; GACATCCCTGAAGTCAGCTGC, reverse;

TCCCTTGGGTCCCTCGAC). Specificity of amplification was verified by the presence of a single peak on the dissociation curve. Amplification conditions are available upon request. Measurements were performed in triplicate and from at least 3 independent experiments. 
For genotyping, genomic DNA was isolated from tail tips by sodium hydroxide digestion, and PCR was performed using primers $\mathrm{P} 1, \mathrm{P} 2$ and $\mathrm{P} 4$, as described by Zhu et al ${ }^{54}$. The Col2a1 collagen-Cre transgene was detected using the fwd:

GAGTTGATAGCTGGCTGGTGGCAGATG and reverse: TCCTCCTGCTCCTAGGGCCTCCTGCAT primers.

\section{Western blot analyses}

Whole cell lysates were separated by SDS-PAGE electrophoresis according to standard protocols. Nitrocellulose membranes were probed with the indicated antibody using standard protocols (monoclonal anti- $\beta$-actin antibody (Sigma cat\# AC-74, dilution 1: 5000), antiPhospho-Smad1/5 antibody (Cell Signaling cat\#9516S, dilution 1:1000), antiSmad1+Smad5 antibody (Abcam cat\# ab75273, dilution 1:1000), anti ENPP1/PC-1 (Aviva Systems Biology, cat\# OAEB02445, dilution 1:500) and anti-ANK (Origen, cat\# TA325111, dilution 1:1000).

\section{Histology}

Static histomorphometry measurements were performed as previously described in accordance with standard nomenclature ${ }^{60}$, using the Bioquant Analysis System (Nashville, TN, USA) on $5 \mu \mathrm{m}$ undecalcified methymethacrylate sections. Calcified cartilage BV/TV was measured in the growth plate hypertrophic region following von Kossa and van Gieson staining.

\section{X-rays and $\mu \mathrm{CT}$ analyses}

Radiographs were obtained using a digital cabinet X-ray system (LX-60, Faxitron X-Ray, USA). $\mu \mathrm{CT}$ analyses were performed using a Scanco $\mu \mathrm{CT} 40$ system (Scanco Medical, Bassersdorf, Switzerland). Tomographic images were acquired at $55 \mathrm{kVp}$ and $145 \mathrm{~mA}$ with an isotropic voxel size of $12 \mu \mathrm{m}$ and at an integration time of $250 \mathrm{~ms}$ with 500 projections collected per $180^{\circ}$ rotation.

\section{Raman Spectroscopy}

To ensure anatomic consistency of data collection site among bones of differing length, midshaft vessel perforations were used as landmarks. Spectra were obtained with 5 accumulations of $20 \mathrm{~s}$ exposures with $20 \mathrm{~mW}$ laser power at a spot size of $1.5 \mu \mathrm{m}$ in diameter. Spectra were processed via least squares modified polynomial fit ${ }^{61}$ and smoothed for noise using an $2^{\text {nd }}$ order Savitsky-Golay filter ${ }^{62}$. System Raman shift calibration was accomplished using a neon lamp and a silicon standard. Silicon standard measurements before and after data acquisition ensured wavenumber calibration consistency. Spectral intensities for known Raman peaks and peak ratios were extracted using custom Matlab software (Mathworks, Natick, MA) to generate markers of bone composition for mineralization (v1 Phosphate/Proline) and crystallinity (crystal grain size and perfection, determined by the inverse full-width at half maximum intensity of the v1 Phosphate peak). 


\section{Biomechanical Testing}

Hydrated samples were tested in three-point bending with a span of $8 \mathrm{~mm}$ at a rate of 3 $\mathrm{mm} \cdot \mathrm{min}^{-1}$ as per ${ }^{63}$. Force and displacement was measured from a $100 \mathrm{~N}$ load cell, and from the linear variable displacement transformer of the material testing system (Dynamight 8841, Instron, Canton, OH). Structural properties were extracted from force-displacement curves by custom Matlab algorithms (Mathworks, Natick, MA). Material properties were calculated by accounting for structure by utilizing cross-sectional area and moment of inertia as measured by $\mu \mathrm{CT}$.

\section{Statistical analysis}

Depending on whether data per group passed the Shapiro-Wilk normality test or whether standard deviations were not different among the groups (Bartlett's test), one-way analysis of variance (ANOVA) or the Kruskal-Wallis Test (non-parametric) was used to determine whether differences existed in $\mu \mathrm{CT}$-, Raman-, and biomechanical-derived properties among the experimental groups. When differences existed at $p<0.05$, post-hoc, pair-wise comparisons were tested for significance in which the $\mathrm{p}$-value was adjusted $\left(p_{\text {adj }}<0.05\right)$ by Holm-Sidak's method or Dunn's method (non-parametric). Statistical analysis was performed using GraphPad PRISM (v6.0a, La Jolla, CA). Data are provided as mean +/$\mathrm{SD}$.

\section{Supplementary Material}

Refer to Web version on PubMed Central for supplementary material.

\section{Acknowledgments}

We thank Drs. A. Bianchi and F. Cailotto for their help in establishing the PPi measurement protocol and K.S. Campbell for editorial assistance. This work was supported by a Young Investigator Award 2012-01-028 from the Children's Tumor Foundation JN, the US National Institute of Arthritis and Musculoskeletal and Skin Diseases and National Center for Research Resources, part of the National Institutes of Health, under Award Number 5R01 AR055966 FE and S10 RR027631 DSP, the Pediatric Orthopaedic Society of North American and Texas Scottish Rite Hospital for Children JJR and the U.S. Army Medical Research Acquisition Activity under award W81XWH11-1-0250 DAS.

\section{References}

1. Huson SM, Compston DA, Clark P, Harper PS. A genetic study of von Recklinghausen neurofibromatosis in south east Wales. I. Prevalence, fitness, mutation rate, and effect of parental transmission on severity. Journal of medical genetics. 26:704-711.1989; [PubMed: 2511318]

2. Stevenson DA, et al. Approaches to treating NF1 tibial pseudarthrosis: consensus from the Children's Tumor Foundation NF1 Bone Abnormalities Consortium. J Pediatr Orthop. 33:269275.2013; [PubMed: 23482262]

3. Elefteriou F, et al. Skeletal abnormalities in neurofibromatosis type 1: approaches to therapeutic options. American journal of medical genetics. Part A. 149A:2327-2338.2009; [PubMed: 19764036]

4. Kuorilehto T, et al. Decreased bone mineral density and content in neurofibromatosis type 1: lowest local values are located in the load-carrying parts of the body. Osteoporosis international. 16:928936.2005; [PubMed: 15551055]

5. Stevenson DA, et al. Bone mineral density in children and adolescents with neurofibromatosis type 1. J Pediatr. 150:83-88.2007; [PubMed: 17188620] 
6. Duman O, et al. Bone metabolism markers and bone mineral density in children with neurofibromatosis type-1. Brain \& development. 30:584-588.2008; [PubMed: 18362054]

7. Vitale MG, Guha A, Skaggs DL. Orthopaedic manifestations of neurofibromatosis in children: an update. Clinical orthopaedics and related research. :107-118.2002

8. Stevenson DA, et al. Descriptive analysis of tibial pseudarthrosis in patients with neurofibromatosis 1. American journal of medical genetics. 84:413-419.1999; [PubMed: 10360395]

9. Neitzschman HR, Costelloe CM, Willis RB, De Mouy EH. Radiology case of the month. Congenital bone disorder associated with deformity, fracture, and pseudoarthrosis. Congenital tibial dysplasia-neurofibromatosis type I NF1. The Journal of the Louisiana State Medical Society. 153:119_ 121.2001; [PubMed: 11355506]

10. Ippolito E, Corsi A, Grill F, Wientroub S, Bianco P. Pathology of bone lesions associated with congenital pseudarthrosis of the leg. Journal of pediatric orthopedics. Part B. 9:3-10.2000; [PubMed: 10647102]

11. Stevenson DA, et al. Double inactivation of NF1 in tibial pseudarthrosis. American journal of human genetics. 79:143-148.2006; [PubMed: 16773574]

12. Kolanczyk M, et al. Multiple roles for neurofibromin in skeletal development and growth. Human molecular genetics. 16:874-886.2007; [PubMed: 17317783]

13. Sullivan K, El-Hoss J, Little DG, Schindeler A. JNK inhibitors increase osteogenesis in Nf1deficient cells. Bone. 49:1311-1316.2011; [PubMed: 21964323]

14. Lee DY, et al. Disturbed osteoblastic differentiation of fibrous hamartoma cell from congenital pseudarthrosis of the tibia associated with neurofibromatosis type I. Clinics in orthopedic surgery. 3:230-237.2011; [PubMed: 21909471]

15. Leskela HV, et al. Congenital pseudarthrosis of neurofibromatosis type 1: impaired osteoblast differentiation and function and altered NF1 gene expression. Bone. 44:243-250.2009; [PubMed: 19061981]

16. Wu X, et al. Neurofibromin plays a critical role in modulating osteoblast differentiation of mesenchymal stem/progenitor cells. Human molecular genetics. 15:2837-2845.2006; [PubMed: 16893911]

17. Kuhnisch J, et al. Multiscale, Converging Defects of Macro-Porosity, Microstructure and Matrix Mineralization Impact Long Bone Fragility in NF1. PloS one. 9:e86115.2014; [PubMed: 24465906]

18. Elefteriou F, et al. ATF4 mediation of NF1 functions in osteoblast reveals a nutritional basis for congenital skeletal dysplasiae. Cell metabolism. 4:441-451.2006; [PubMed: 17141628]

19. Rhodes SD, et al. Hyperactive transforming growth factor-beta1 signaling potentiates skeletal defects in a neurofibromatosis type 1 mouse model. J Bone Miner Res. 28:2476-89.2013; [PubMed: 23703870]

20. Seitz S, et al. High bone turnover and accumulation of osteoid in patients with neurofibromatosis 1 . Osteoporosis international. 21:119-127.2010; [PubMed: 19415373]

21. Johnson K, et al. Linked deficiencies in extracellular PPi and osteopontin mediate pathologic calcification associated with defective PC-1 and ANK expression. Journal of bone and mineral research. 18:994-1004.2003; [PubMed: 12817751]

22. Terkeltaub RA. Inorganic pyrophosphate generation and disposition in pathophysiology. American journal of physiology. Cell physiology. 281:C1-C11.2001; [PubMed: 11401820]

23. Macrae VE, et al. Inhibition of PHOSPHO1 activity results in impaired skeletal mineralization during limb development of the chick. Bone. 46:1146-1155.2010; [PubMed: 20053388]

24. Harmey D, et al. Concerted regulation of inorganic pyrophosphate and osteopontin by akp2, enpp1, and ank: an integrated model of the pathogenesis of mineralization disorders. The American journal of pathology. 164:1199-1209.2004; [PubMed: 15039209]

25. Addison WN, Azari F, Sorensen ES, Kaartinen MT, McKee MD. Pyrophosphate inhibits mineralization of osteoblast cultures by binding to mineral, up-regulating osteopontin, and inhibiting alkaline phosphatase activity. J Biol Chem. 282:15872-15883.2007; [PubMed: 17383965]

26. Sowa H, Kaji H, Yamaguchi T, Sugimoto T, Chihara K. Activations of ERK1/2 and JNK by transforming growth factor beta negatively regulate Smad3-induced alkaline phosphatase activity 
and mineralization in mouse osteoblastic cells. The Journal of biological chemistry. 277:3602436031.2002; [PubMed: 12130649]

27. Lian N, et al. Transforming growth factor beta suppresses osteoblast differentiation via the vimentin activating transcription factor 4 ATF4 axis. The Journal of biological chemistry. 287:35975-35984.2012; [PubMed: 22952236]

28. Terkeltaub RA, et al. Bone morphogenetic proteins and bFGF exert opposing regulatory effects on PTHrP expression and inorganic pyrophosphate elaboration in immortalized murine endochondral hypertrophic chondrocytes MCT cells. Journal of bone and mineral research. 13:931-941.1998; [PubMed: 9626624]

29. Alves RD, Eijken M, Bezstarosti K, Demmers JA, van Leeuwen JP. Activin A suppresses osteoblast mineralization capacity by altering extracellular matrix composition and impairing matrix vesicle production. Molecular \& cellular proteomics : MCP. 2013

30. Zhang M, et al. Osteoblast-specific knockout of the insulin-like growth factor IGF receptor gene reveals an essential role of IGF signaling in bone matrix mineralization. The Journal of biological chemistry. 277:44005-44012.2002; [PubMed: 12215457]

31. Kyono A, Avishai N, Ouyang Z, Landreth GE, Murakami S. FGF and ERK signaling coordinately regulate mineralization-related genes and play essential roles in osteocyte differentiation. Journal of bone and mineral metabolism. 30:19-30.2012; [PubMed: 21678127]

32. Hatch NE, Nociti F, Swanson E, Bothwell M, Somerman M. FGF2 alters expression of the pyrophosphate/phosphate regulating proteins, PC-1, ANK and TNAP, in the calvarial osteoblastic cell line, MC3T3E1C4. Connective tissue research. 46:184-192.2005; [PubMed: 16546821]

33. Wang $\mathrm{H}$, et al. Overexpression of fibroblast growth factor 23 suppresses osteoblast differentiation and matrix mineralization in vitro. Journal of bone and mineral research. 23:939-948.2008; [PubMed: 18282132]

34. Liu S, Tang W, Zhou J, Vierthaler L, Quarles LD. Distinct roles for intrinsic osteocyte abnormalities and systemic factors in regulation of FGF23 and bone mineralization in Hyp mice. American journal of physiology. Endocrinology and metabolism. 293:E1636-1644.2007; [PubMed: 17848631]

35. Le LQ, Parada LF. Tumor microenvironment and neurofibromatosis type I: connecting the GAPs. Oncogene. 26:4609-4616.2007; [PubMed: 17297459]

36. Wang W, et al. Local low-dose lovastatin delivery improves the bone-healing defect caused by Nf1 loss of function in osteoblasts. Journal of bone and mineral research : the official journal of the American Society for Bone and Mineral Research. 25:1658-1667.2010;

37. Wang W, et al. Mice lacking Nf1 in osteochondroprogenitor cells display skeletal dysplasia similar to patients with neurofibromatosis type I. Human molecular genetics. 20:3910-3924.2011; [PubMed: 21757497]

38. Ono K, et al. The Ras-GTPase activity of neurofibromin restrains ERK-dependent FGFR signaling during endochondral bone formation. Human molecular genetics. 22:3048-62.2013; [PubMed: 23571107]

39. Lecanda F, Avioli LV, Cheng SL. Regulation of bone matrix protein expression and induction of differentiation of human osteoblasts and human bone marrow stromal cells by bone morphogenetic protein-2. Journal of cellular biochemistry. 67:386-396.1997; [PubMed: 9361193]

40. Schindeler A, et al. Modeling bone morphogenetic protein and bisphosphonate combination therapy in wild-type and Nf1 haploinsufficient mice. Journal of orthopaedic research. 26:6574.2008; [PubMed: 17787010]

41. Schindeler A, et al. Distal tibial fracture repair in a neurofibromatosis type 1-deficient mouse treated with recombinant bone morphogenetic protein and a bisphosphonate. The Journal of bone and joint surgery. British volume. 93:1134-1139.2011; [PubMed: 21768643]

42. Whyte MP, et al. Enzyme-replacement therapy in life-threatening hypophosphatasia. The New England journal of medicine. 366:904-913.2012; [PubMed: 22397652]

43. Whyte MP. Physiological role of alkaline phosphatase explored in hypophosphatasia. Annals of the New York Academy of Sciences. 1192:190-200.2010; [PubMed: 20392236]

44. Yadav MC, et al. Enzyme replacement prevents enamel defects in hypophosphatasia mice. Journal of bone and mineral research. 27:1722-1734.2012; [PubMed: 22461224] 
45. Yadav MC, et al. Dose response of bone-targeted enzyme replacement for murine hypophosphatasia. Bone. 49:250-256.2011; [PubMed: 21458605]

46. Rodda SJ, McMahon AP. Distinct roles for Hedgehog and canonical Wnt signaling in specification, differentiation and maintenance of osteoblast progenitors. Development. 133:3231-3244.2006; [PubMed: 16854976]

47. Zhu Y, et al. Ablation of NF1 function in neurons induces abnormal development of cerebral cortex and reactive gliosis in the brain. Genes \& development. 15:859-876.2001; [PubMed: 11297510]

48. Sohn P, Crowley M, Slattery E, Serra R. Developmental and TGF-beta-mediated regulation of Ank mRNA expression in cartilage and bone. Osteoarthritis and cartilage/OARS, Osteoarthritis Research Society. 10:482-490.2002;

49. Cailotto F, Sebillaud S, Netter P, Jouzeau JY, Bianchi A. The inorganic pyrophosphate transporter ANK preserves the differentiated phenotype of articular chondrocyte. The Journal of biological chemistry. 285:10572-10582.2010; [PubMed: 20133941]

50. Larizza L, Gervasini C, Natacci F, Riva P. Developmental abnormalities and cancer predisposition in neurofibromatosis type 1. Current molecular medicine. 9:634-653.2009; [PubMed: 19601812]

51. Anticevic D, Jelic M, Vukicevic S. Treatment of a congenital pseudarthrosis of the tibia by osteogenic protein-1 bone morphogenetic protein-7: a case report. Journal of pediatric orthopedics. Part B. 15:220-221.2006; [PubMed: 16601593]

52. Lee FY, et al. Treatment of congenital pseudarthrosis of the tibia with recombinant human bone morphogenetic protein-7 rhBMP-7. A report of five cases. The Journal of bone and joint surgery. American volume. 88:627-633.2006; [PubMed: 16510831]

53. Fabeck L, Ghafil D, Gerroudj M, Baillon R, Delince P. Bone morphogenetic protein 7 in the treatment of congenital pseudarthrosis of the tibia. The Journal of bone and joint surgery. British volume. 88:116-118.2006; [PubMed: 16365133]

54. Zhu Y, et al. Ablation of NF1 function in neurons induces abnormal development of cerebral cortex and reactive gliosis in the brain. Genes Dev. 15:859-876.2001; [PubMed: 11297510]

55. Ovchinnikov DA, Deng JM, Ogunrinu G, Behringer RR. Col2a1-directed expression of Cre recombinase in differentiating chondrocytes in transgenic mice. Genesis. 26:145-146.2000; [PubMed: 10686612]

56. Millan JL, et al. Enzyme replacement therapy for murine hypophosphatasia. Journal of bone and mineral research. 23:777-787.2008; [PubMed: 18086009]

57. Granchi D, et al. Biological basis for the use of autologous bone marrow stromal cells in the treatment of congenital pseudarthrosis of the tibia. Bone. 46:780-788.2010; [PubMed: 19900596]

58. Terkeltaub R, Rosenbach M, Fong F, Goding J. Causal link between nucleotide pyrophosphohydrolase overactivity and increased intracellular inorganic pyrophosphate generation demonstrated by transfection of cultured fibroblasts and osteoblasts with plasma cell membrane glycoprotein-1. Relevance to calcium pyrophosphate dihydrate deposition disease. Arthritis and rheumatism. 37:934-941.1994; [PubMed: 8003067]

59. Cailotto F, et al. Inorganic pyrophosphate generation by transforming growth factor-beta- 1 is mainly dependent on ANK induction by Ras/Raf-1/extracellular signal-regulated kinase pathways in chondrocytes. Arthritis research \& therapy. 9:R122.2007; [PubMed: 18034874]

60. Parfitt AM, et al. Bone histomorphometry: standardization of nomenclature, symbols, and units. Report of the ASBMR Histomorphometry Nomenclature Committee. Journal of bone and mineral research. 2:595-610.1987; [PubMed: 3455637]

61. Lieber CA, Mahadevan-Jansen A. Automated method for subtraction of fluorescence from biological Raman spectra. Applied spectroscopy. 57:1363-1367.2003; [PubMed: 14658149]

62. Maher JR, Takahata M, Awad HA, Berger AJ. Raman spectroscopy detects deterioration in biomechanical properties of bone in a glucocorticoid-treated mouse model of rheumatoid arthritis. Journal of biomedical optics. 16:087012.2011; [PubMed: 21895339]

63. Makowski AJ, et al. The loss of activating transcription factor 4 ATF4 reduces bone toughness and fracture toughness. Bone. 62C:1-9.2014; 
a

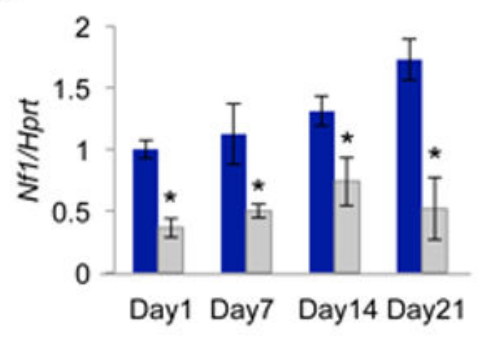

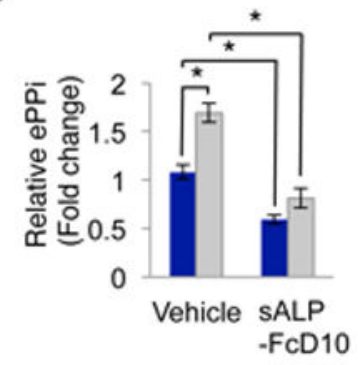

C
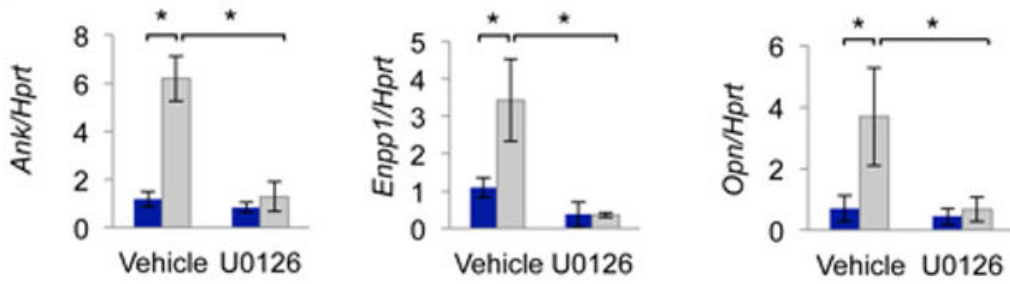

d
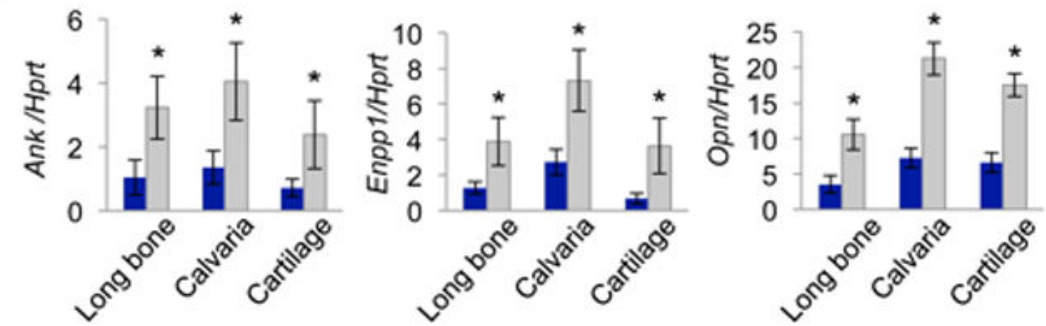

e
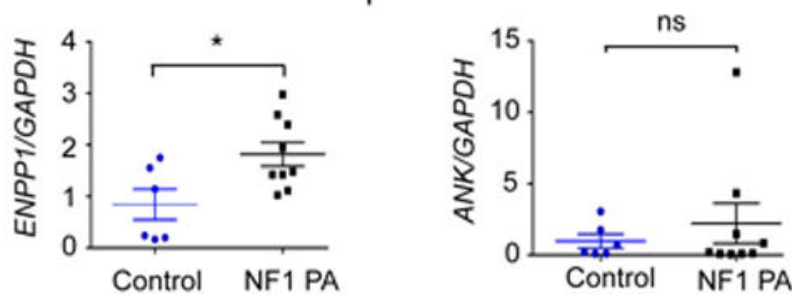

Figure 1. Uncontrolled Ank, Enpp1, Opn expression and increased pyrophosphate production in Nf1-deficient osteoblasts

(a) Nf1 mRNA expression in BMSCs differentiated for 7, 14 and 21 days $(n=3)$. (b) Extracellular PPi concentration in the conditioned medium of undifferentiated BMSCs $(n=$ 3). (c) Ank, Enpp1 and Opn mRNA expression in BMSCs treated with vehicle (DMSO) or U0126 for $24 \mathrm{~h}(n=3)$. (d). Ank, Enpp1 and Opn mRNA expression in long bones, calvariae and epiphyses of 3 week-old WT (blue bars) and Col2-Nf1 KO mice (grey bars) $(n=6)$. (e, f) $E N P P 1$ and $A N K$ mRNA expression in bone marrow adherent cells from control $(n=6)$ and NF1 pseudarthrosis (PA, $n=9$ ) biopsies. Blue bars: BMSCs from WT mice, grey bars: BMSCs from Col2-Nf1 KO mice, *: $p<0.05$. ns: non-significant. 
a

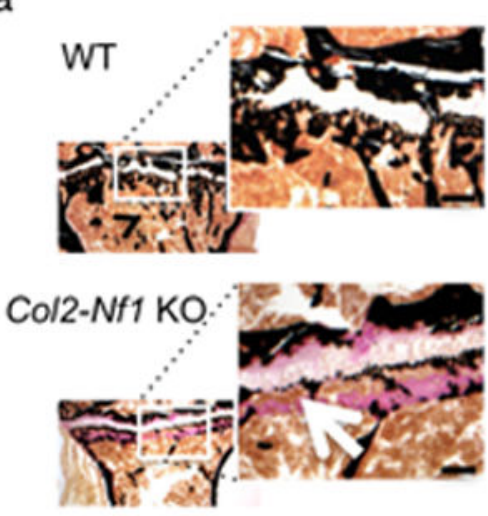

b

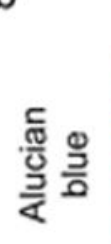

C

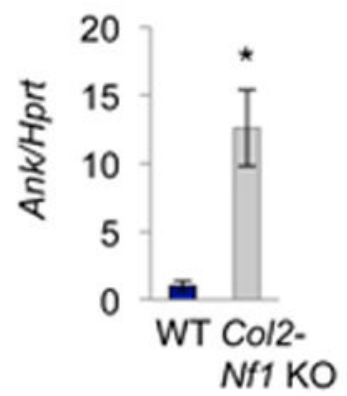

d

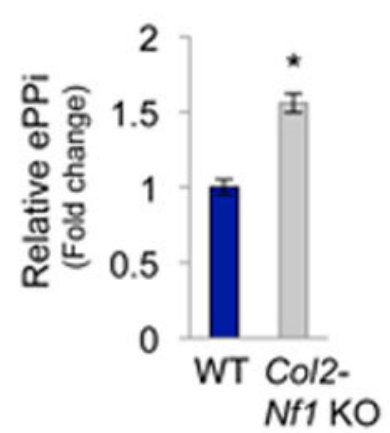

e

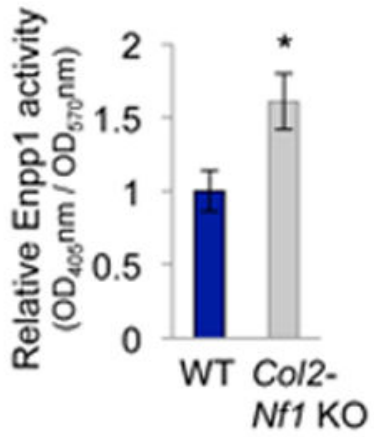

WT

$N f 1^{\%}$
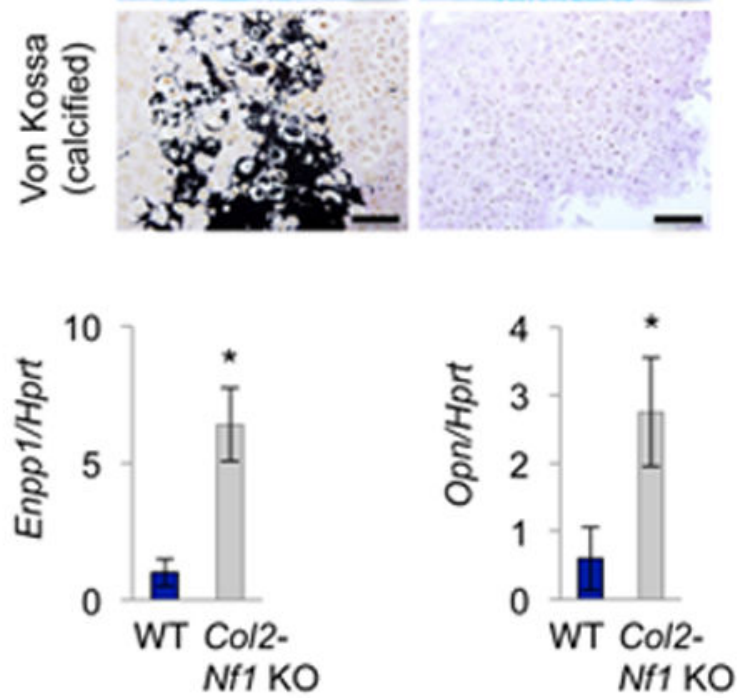

f

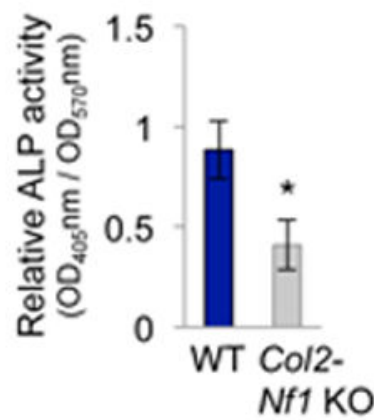

Figure 2. Altered pyrophosphate homeostasis in $\mathbf{N f 1 - d e f i c i e n t ~ c h o n d r o c y t e s ~}$ (a) Hyperosteoidosis (pink, white arrow) in the primary spongiosa from $\mathrm{Col2}-\mathrm{Nf1} \mathrm{KO}^{-1-}$ mice (undecalcified sections stained by von Kossa/Van Gieson, bar: $150 \mu \mathrm{m}$ ). (b) Highdensity chondrocyte pellets prepared from WT and Col2-Nf1 KO pups. Proteoglycan production (top panels, Alcian blue staining) and matrix mineralization (bottom panels, von Kossa staining) $(n=3$. bar: $100 \mu \mathrm{m})$. (c) Ank, Enpp1 and Opn mRNA expression in highdensity chondrocyte pellets $(n=3)$. (d) Relative extracellular PPi concentration, (e) ENPP1 activity and (f) ALP activity in WT and Col2-Nf1 KO high-density chondrocytes pellets ( $n$ $=3)$. $*: p<0.05$. 
a
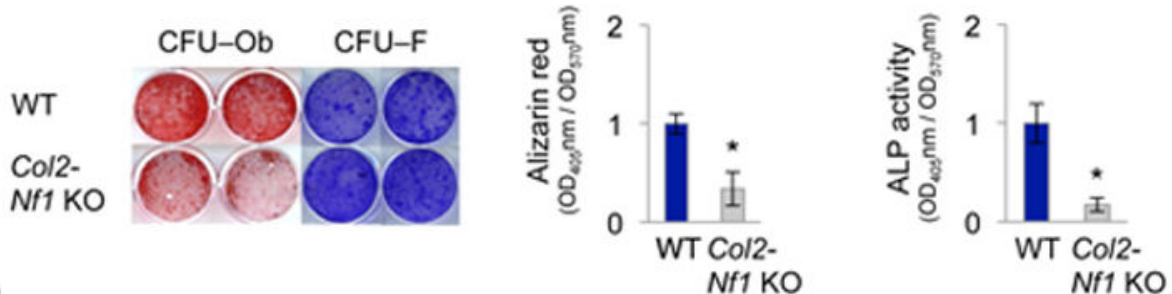

b
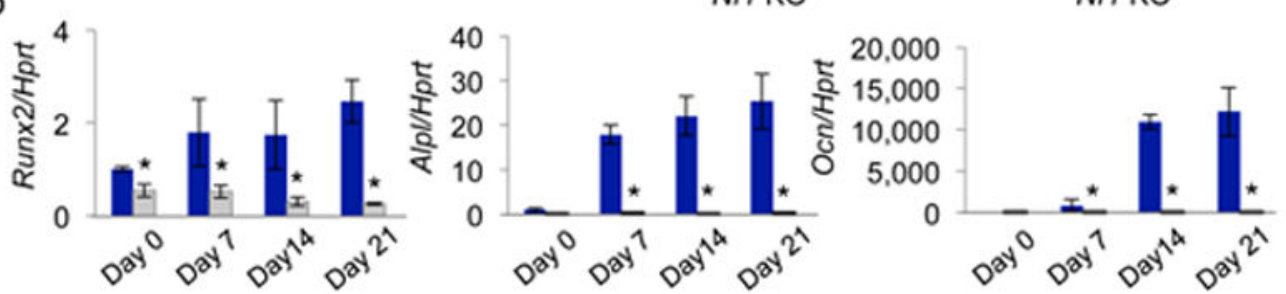

C
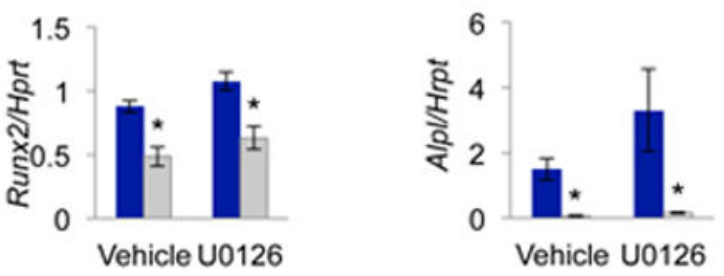

d

e
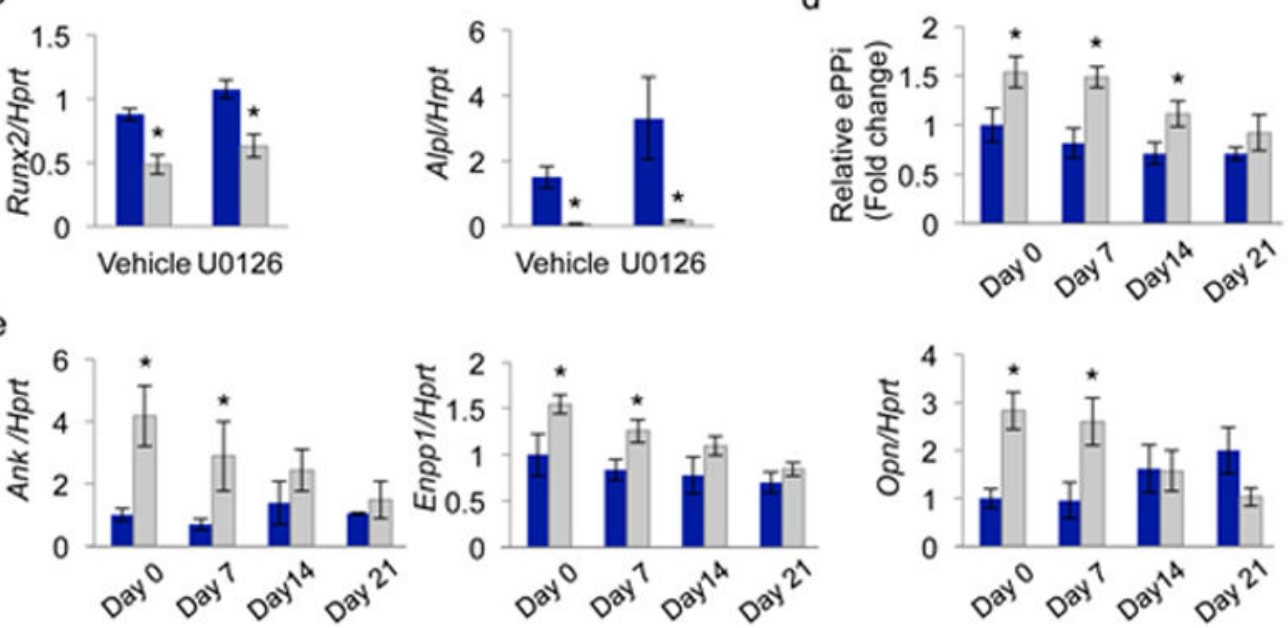

Figure 3. Blunted BMP2 response and osteoblast differentiation potential in Nf1-deficient osteoprogenitors

(a) BMSC differentiation analyzed by Alizarin red-S (differentiation/mineralization, CFU$\mathrm{Ob}$ ), crystal violet staining (cell number, CFU-F, left panel), soluble Alizarin redS/crystal violet optical density ratio (middle panel) and ALP activity/crystal violet ratio (right panel) $(n=6)$. (b) Runx2, Alpl and Ocn mRNA expression in BMSCs differentiated for 7, 14 and 21 days $(n=4)$. (c) Runx 2 and Alpl mRNA expression in serum-starved BMSCs treated with vehicle (DMSO) or U0126 for $24 \mathrm{~h}(n=6)$. (d) Extracellular PPi concentration/protein concentration in BMSCs differentiated for 7, 14 and 21 days $(n=4)$. (e) Normalized $A n k$, Enpp1 and Opn mRNA expression in BMSCs differentiated for 7, 14 and 21 days $(n=4)$. Blue bars: WT mice, grey bars: Col2-Nf1 KO mice, * $p<0.05$. 

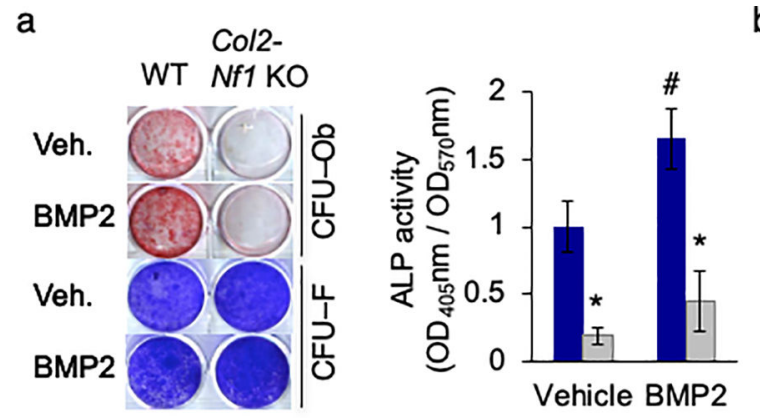

b

C
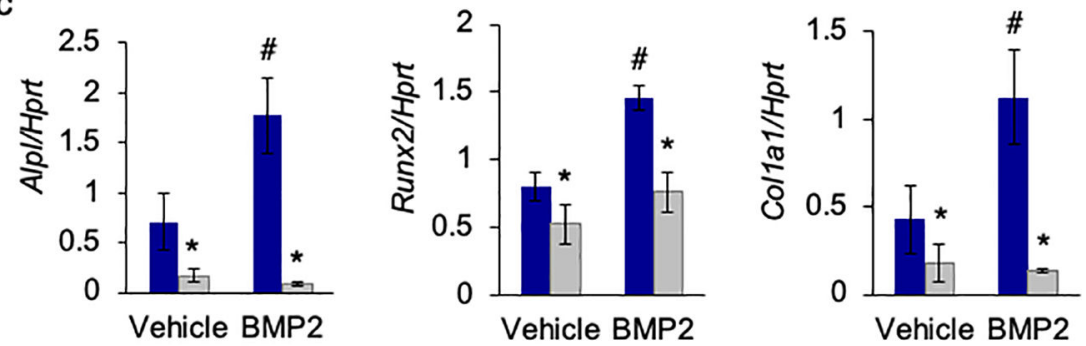

d
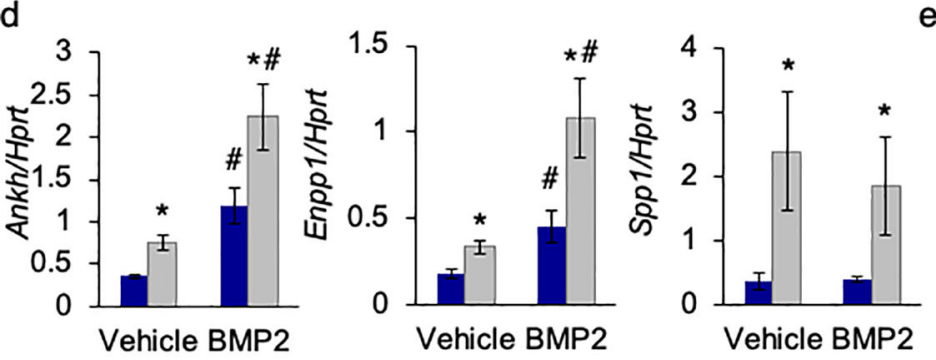

e

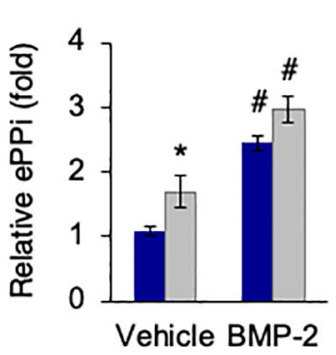

f

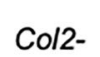

WT Nf1 KO WT Nf1 KO
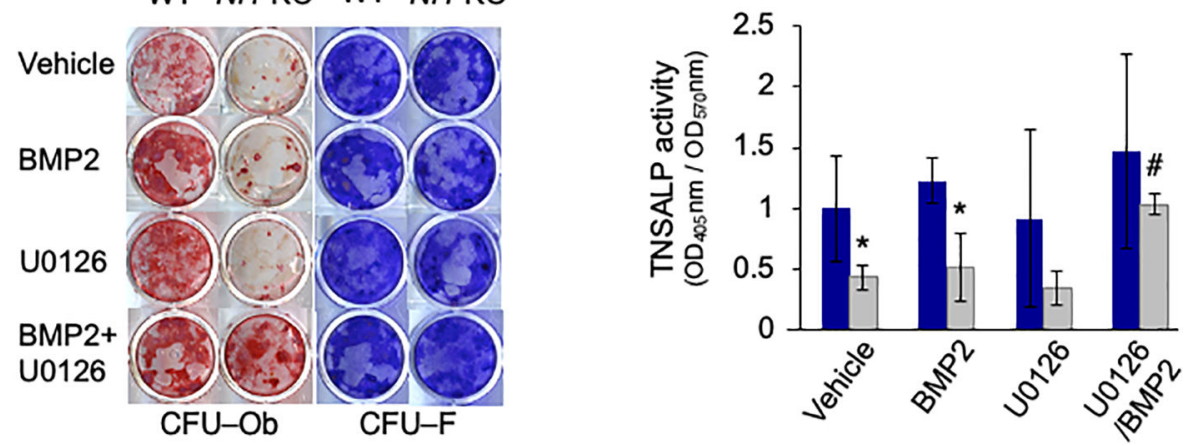

Figure 4. BMP2 does not promote differentiation in $\mathrm{Nf1}$-deficient BMSCs but exacerbates their mineralization deficit

(a) BMSC differentiation analyzed by Alizarin red-S (differentiation/mineralization, CFU$\mathrm{Ob})$ and crystal violet (cell number, CFU-F) staining $(n=3)$ and ALP activity $(n=3)$, following vehicle or BMP2 treatment. (b) Phospho-Smad1/5 induction in serum-starved BMSCs following BMP2 treatment for $1 \mathrm{~h}$. Smad1/5 and $\beta$-actin served as loading control. (c and d) Alpl, Runx2, Col1a1, Ank, Enpp1 and Opn mRNA expression following BMP2 treatment for 2 weeks $(n=3)$. (e) Extracellular PPi relative concentration (normalized to 
protein concentration) in the conditioned medium of BMSCs treated with BMP2 for $24 \mathrm{~h}$ ( $n$ $=3$ ). (f and $\mathbf{g}$ ) BMSC differentiation analyzed by Alizarin red-S (differentiation/ mineralization, CFU-Ob) and crystal violet (cell number, CFU-F) staining (f, $n=3$ ) and ALP activity $(\mathbf{g}, n=3)$ following treatment with vehicle or BMP2 or U0126 or both for 2 weeks. Blue bars: WT mice; grey bars: Col2-Nf1 KO mice. *: $p<0.05$ versus WT in the same treatment group; \#: $p<0.05$ versus vehicle in the same genotype group. 
a

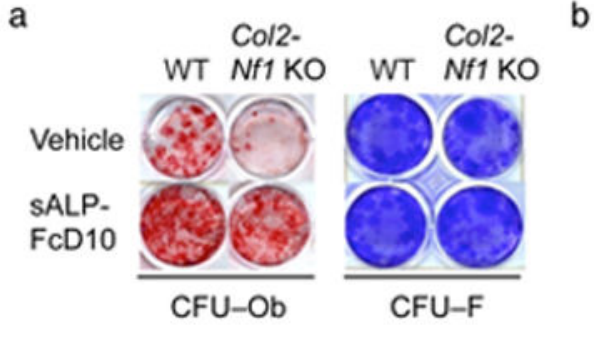

C
WT

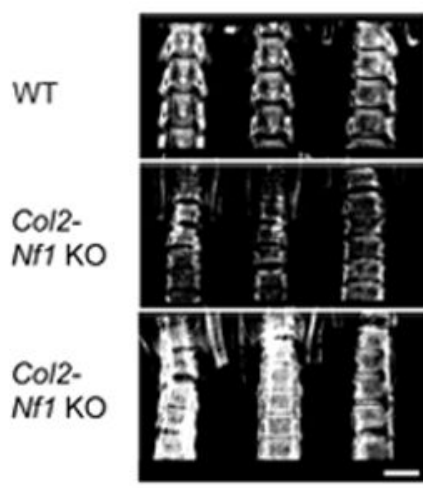

e

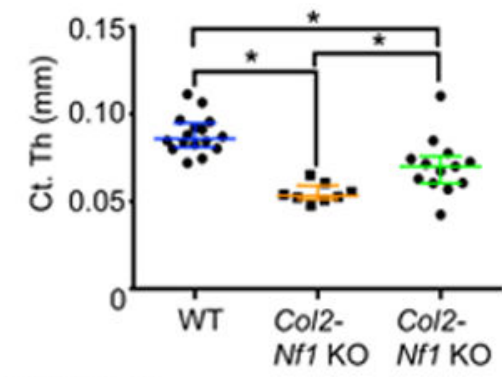
KO mice b

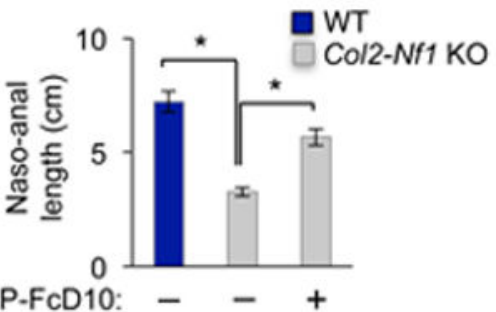

d
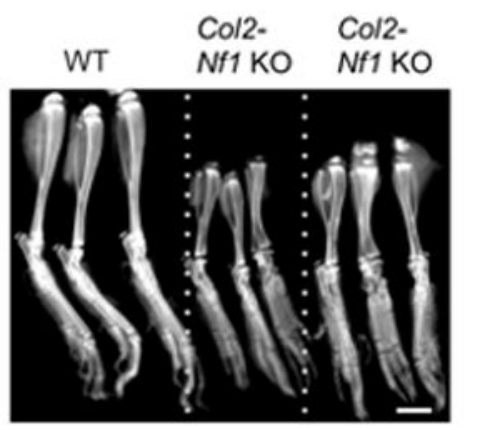

SALP-FCD10: - $\quad-\quad+$

f

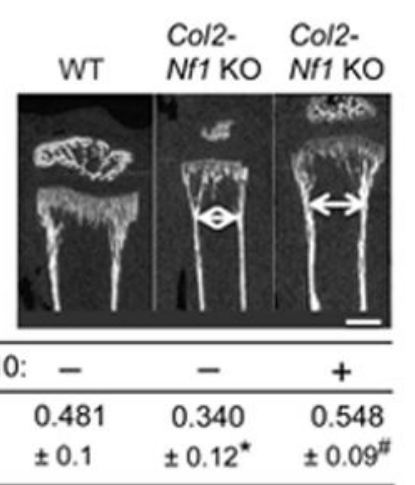

Figure 5. sALP-FcD10 improves bone growth and cortical bone parameters in growing Col2-NfI

(a) BMSC matrix mineralization (CFU-Ob) and number (CFU-F) analyzed by Alizarin red$\mathrm{S}$ and crystal violet staining, respectively $(n=3)$ following vehicle or sALP-FcD10 treatment for 2 weeks. (b-f) Bone growth (b, naso-anal length), vertebral (c, bar: $250 \mu \mathrm{m})$ and tibial (d, bar: $250 \mu \mathrm{m})$ bone mineral density (X-rays), cortical thickness (e, Ct.Th, $\mu \mathrm{CT}$ ), epiphyseal diameter (f, white arrow, bar: $45 \mu \mathrm{m}, \mu \mathrm{CT}$ ) and hypertrophic zone von Kossapositive calcified Bone Volume/Tissue Volume (hBV/TV, histology) in Col2-Nf1 KO newborn pups treated daily by sALP-FcD10 for 18 days ( $n>8$ mice/group). * $p<0.05$ versus WT; \#: $p<0.05$ versus vehicle in the same genotype group. 
a

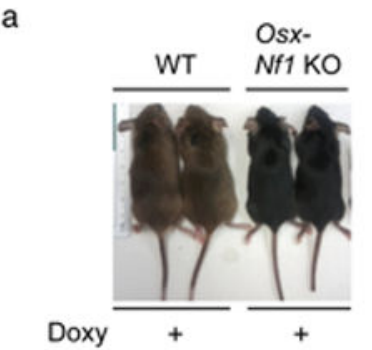

b

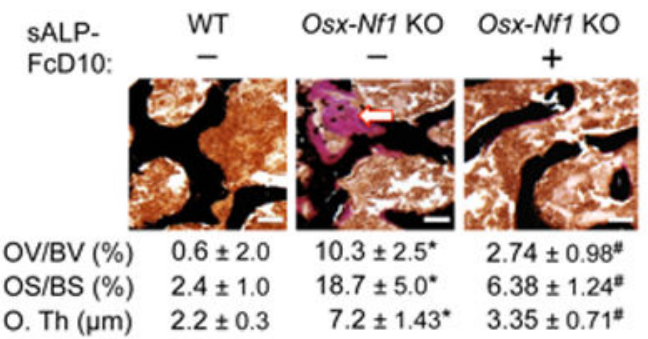

C

d
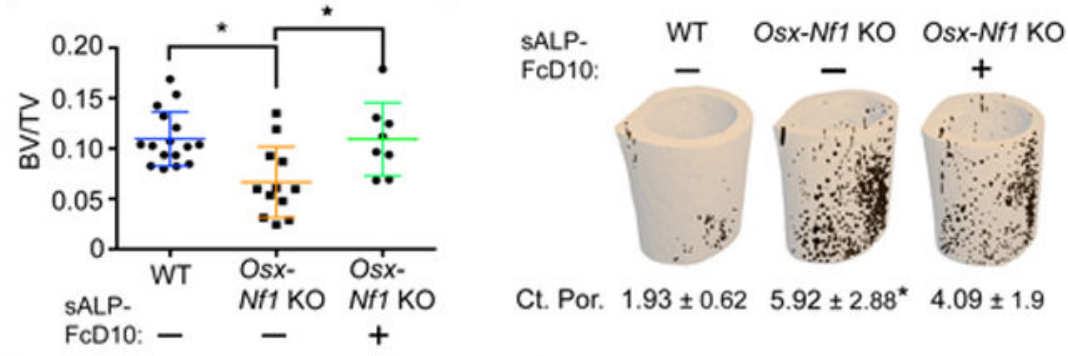

e

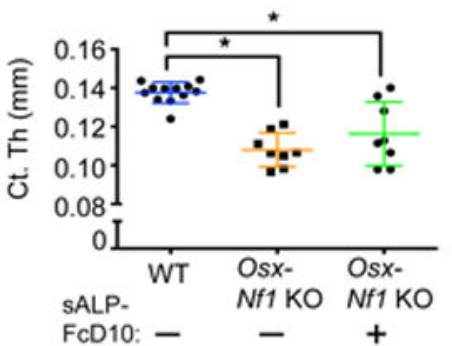

g

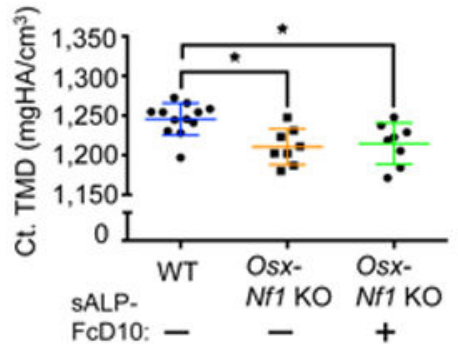

Ct. Por. $1.93 \pm 0.62 \quad 5.92 \pm 2.88^{\star} \quad 4.09 \pm 1.9$

f

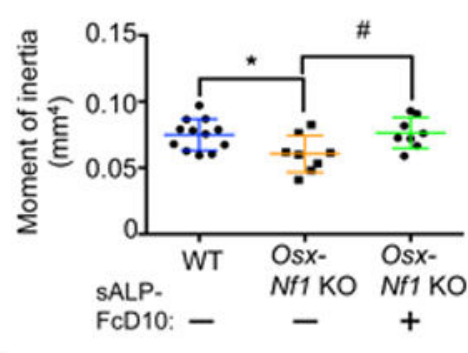

h

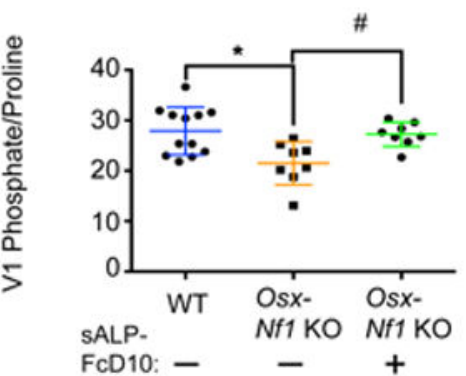

Figure 6. sALP-FcD10 improves trabecular bone mass, mineralization and bone structure in Os $x$-Nf1 KO mice

(a) Size of two month-old WT and $O s x-N f 1 K O$ mice following doxycycline (Doxy) treatment from conception to P14. (b) Femoral hyperosteoidosis (pink stain following von Kossa/van Gieson staining), Osteoid Volume/Bone Volume ratio (OV/BV), Osteoid Surface/ Bone Surface ratio (OS/BS) and Osteoid Thickness (O. Th) in WT and OsX-Nf1 KO mice and rescue by sALP-FcD10 administration for 6 weeks (histomorphometric analyses, bar: $150 \mu \mathrm{m})$. (c) Femoral Bone Volume/Tissue Volume (BV/TV) in WT and Os $x$ - $N f 1 \mathrm{KO}$ mice and rescue by sALP-FcD10 administration $(\mu \mathrm{CT})$. (d) Cortical porosity in $O s X-N f 1 \mathrm{KO}$ mice and partial beneficial effect of sALP-FcD10 administration $(\mu \mathrm{CT})$. (e) Femoral cortical thickness in WT and $O s x-N f 1 \mathrm{KO}$ mice $(\mu \mathrm{CT})$. (f) Moment of inertia in WT and $O s x-N f 1$ $\mathrm{KO}$ mice and rescue by sALP-FcD10 administration $(\mu \mathrm{CT})$. (g) Cortical Tissue Mineral 
Density (TMD) in WT and $O s x-N f 1$ KO mice $(\mu \mathrm{CT})$. (h) Mineral-to-Collagen ratio $(\nu 1$ phosphate/Proline) in WT and $O s x-N f 1$ KO mice and rescue by sALP-FcD10 administration (Raman spectroscopy). ( $n>8$ mice/group). * $p<0.05$ versus WT; \#: $p<0.05$ versus vehicle in the same genotype group. 